\title{
Chemogenetic Excitation of Accumbens-Projecting Infralimbic Cortical Neurons Blocks Toluene-Induced Conditioned Place Preference
}

\author{
Wesley N. Wayman ${ }^{1}$ and $\odot$ John J. Woodward ${ }^{1,2}$ \\ 'Department of Neuroscience and ${ }^{2}$ Department of Psychiatry and Behavioral Sciences, Medical University of South Carolina, Institute of Psychiatry, \\ Charleston, South Carolina 29425
}

\begin{abstract}
Abuse rates for inhalants among adolescents continue to be high, yet preclinical models for studying mechanisms underlying inhalant abuse remain limited. Our laboratory has previously shown that, in male rats, an acute binge-like exposure to toluene vapor that mimics human solvent abuse modifies the intrinsic excitability of mPFC pyramidal neurons projecting to the NAc. These changes showed region (infralimbic; IL vs prelimbic; PRL), layer (shallow; $2 / 3$ vs deep; $5 / 6$ ), target (core vs shell), and age (adolescent vs adult) dependent differences (Wayman and Woodward, 2017). To expand these findings using reward-based models that may better mimic human drug abuse, we used whole-cell electrophysiology and drug receptors exclusively activated by designer drugs to examine changes in neuronal function and behavior in rats showing a conditioned place preference (CPP) to toluene. Repeated pairings of adolescent rats to binge concentrations of toluene vapor previously shown to enhance dopamine release in reward-sensitive areas of the brain produced CPP that persisted for 7 but not $30 \mathrm{~d}$. Toluene-induced CPP was associated with increased excitability of IL5/6 mPFC neurons projecting to the core of the NAc and reduced excitability of those projecting to the NAc shell. No changes in PRL-NAc-projecting neurons were found in toluene-CPP rats. Chemogenetic reversal of the toluene-induced decrease in IL5/6-NAc shell neurons blocked the expression of tolueneinduced CPP while manipulating IL5/6-NAc core neuron activity had no effect. These data reveal that alterations in selective mPFC-NAc pathways are required for expression of toluene-induced CPP.
\end{abstract}

Key words: core; DREADDs; electrophysiology; infralimbic; shell; volatile organic solvent

Significance Statement

Disturbed physiology of pyramidal neurons projecting from the mPFC to the NAc has been shown to have different roles in drug-seeking behaviors for a number of drugs (e.g., methamphetamine, cocaine, ecstasy, alcohol, heroin). Here, we report that rats repeatedly exposed to the volatile organic solvent toluene, a member of the class of abused inhalants often used for intoxicating purposes by adolescents, induces a preference for the drug-paired environment that is accompanied by altered physiology of a specific population of NAcprojecting $\mathrm{mPFC}$ neurons. Chemogenetic correction of this deficit before testing prevented expression of drug preference. Overall, these findings highlight the importance of corticolimbic circuitry in mediating the rewarding properties of abused inhalants.

\section{Introduction}

Inhalants are found in a wide array of household and commercial products, making them easily accessible for abuse, particularly by

\footnotetext{
Received Aug. 31, 2017; revised Dec. 7, 2017; accepted Jan. 4, 2018.

Author contributions: W.N.W. and J.J.W. designed research;W.N.W. performed research;W.N.W. analyzed data; W.N.W. and J.J.W. wrote the paper.

This work was supported by National Institutes of Health Grants R01 DA013951 to J.J.W., F32 DA042518 to W.N.W., and T32 DA 007288. We thank Michael Okas and Kevin Braunscheidel for expert technical assistance with the behavioral studies.

The authors declare no competing financial interests.

Correspondence should be addressed to Dr. John J. Woodward, Department of Neuroscience, Medical University of South Carolina, Institute of Psychiatry, 67 President Street, MSC861, Charleston, SC 29425. E-mail: woodward@musc.edu.
}

adolescents. Adolescence is a critical period for brain development (Spear, 2000), and inhalant abuse during this period may disturb the neurocognitive refinement that takes place during this crucial period (Rosenberg et al., 2002; Crews et al., 2007). Moreover, the mesocorticolimbic reward circuitry of the brain may be particularly vulnerable to misuse of inhalants during this period of development (Wayman and Woodward, 2017). Brain regions that are essential components of the mesocorticolimbic system include the mPFC, NAc, and VTA and drugs of abuse are well-known modifiers of the signaling between these brain regions 
(Lüscher and Malenka, 2011). Although studies investigating the reinforcing properties of toluene remain limited, mounting evidence suggests that toluene abuse produces similar adaptations in reward circuitry. For example, toluene excites VTA DA neurons (Riegel et al., 2007; Nimitvilai et al., 2016), elevates dopamine in the mPFC and NAc (Gerasimov et al., 2002; Koga et al., 2007), and increases markers of plasticity of accumbens-projecting VTA DA neurons (Beckley et al., 2013). In addition, a recent study from our laboratory showed that an acute binge-like exposure of rats to toluene vapor modifies the intrinsic excitability of $\mathrm{MPFC}$ pyramidal neurons projecting to the NAc (Wayman and Woodward, 2017). Inputs from the mPFC to the NAc have been shown to be crucial for allowing associative learning (Block et al., 2007; Burgos-Robles et al., 2013) and recall of reward-related responses to various drugs of abuse, such as cocaine, methamphetamine, and ecstasy (Peters et al., 2009; Rocha and Kalivas, 2010; Ball and Slane, 2012).

Although preclinical models of voluntary administration of volatile solvents are limited, both mice (Blokhina et al., 2004) and nonhuman primates (Weiss et al., 1979) will self-administer toluene intravenously, further validating it as a drug of abuse. However, the intravenous route is not consistent with human patterns of solvent abuse as toluene, and other volatile solvents are typically inhaled at high vapor concentrations resulting in rapid distribution throughout the brain. Because of this, use of animal models of solvent administration that involve inhalation is critical for understanding the maladaptations that may underlie abuse liability and risk of dependency for solvent abuse. In the present study, we used conditioned place preference (CPP), a well-established model for assessing the effects of drug-paired stimuli, to assess the rewarding effects of toluene vapor exposure (Funada et al., 2002; Gerasimov et al., 2003; Lee et al., 2006). This was paired with slice electrophysiology to evaluate alterations in mPFC-NAc neuron physiology that accompany the development of CPP and Cre-dependent chemogenetic manipulations of these pathways to interrogate their role in toluene preference.

The findings of this study show that the CPP produced by repeated exposures to toluene vapor induces reversible and subregion-selective changes in mPFC-NAc reward circuitry and that chemogenetic correction of these changes abolishes the expression of toluene-induced CPP.

\section{Materials and Methods}

Animals. Seventy-two male Sprague Dawley rats were purchased at age P21 from Harlan Laboratories and randomly assigned to air or toluene treatment groups. All rats were pair-housed in an environmentally controlled facility at the Medical University of South Carolina under a $12 \mathrm{~h}$ light/dark cycle. Food and water were provided ad libitum. Rats were handled in accordance with the Medical University of South Carolina Institutional Animal Care and Use Committee protocols.

Retrobead labeling. As previously described (Wayman and Woodward, 2017), fluorescent retrograde tracers (Lumafluor) were injected bilater-

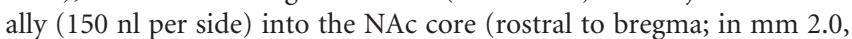
lateral \pm 1.4 , ventral -6.0 ) or NAc shell (rostral to bregma; in mm 2.0, lateral \pm 0.8 , ventral -6.2 ); coordinates modified for age (Paxinos and Watson, 2005) of isoflurane-anesthetized rats aged P29-P30. Rats were allowed to recover in their home cage for a minimum of $7 \mathrm{~d}$ before toluene exposure.

Designer receptors exclusively activated by designer drugs (DREADD)/ Canine adenovirus (CAV) injections. An adeno-associated virus (AAV) virus encoding a Cre-dependent DREADD (AAV8-EF1a-DIO-hM3D (Gq)-mCherry or AAV8-EF1a-DIO-hM4D(Gi)-mCherry; Stanford Viral Core, Palo Alto, CA) or a Cre-dependent fluorescent reporter (AAV8hSyn-DIO-mCherry; Addgene) was injected bilaterally into the infralimbic (IL) cortex (rostral to bregma; $2.8 \mathrm{~mm}$, lateral $\pm 0.5 \mathrm{~mm}$, ventral $-4.4 \mathrm{~mm}$ ) of Sprague Dawley rats (Harlan Laboratories; P29-P30 of age). In the same animal, a retrograde CAV2-Cre virus (Plateforme de Vectorlogie de Montpellier) was injected bilaterally into the NAc core (rostral to bregma; $2.0 \mathrm{~mm}$, lateral $\pm 1.4 \mathrm{~mm}$, ventral $-6.0 \mathrm{~mm}$ ) or NAc shell (rostral to bregma; $2.0 \mathrm{~mm}$, lateral $\pm 0.8 \mathrm{~mm}$, ventral $-6.2 \mathrm{~mm}$ ). Animals were allowed to recover in their home cage for at least $7 \mathrm{~d}$ before toluene exposure.

CPP. The CPP apparatus (Med-Associates) consisted of three distinct chambers: a smaller gray middle chamber with a smooth floor $(21 \mathrm{~cm} \times$ $12 \mathrm{~cm} \times 21 \mathrm{~cm}$ ), a white conditioning chamber with a steel mesh floor $(21 \mathrm{~cm} \times 27 \mathrm{~cm} \times 21 \mathrm{~cm})$, and a black conditioning compartment with a steel bar floor $(21 \mathrm{~cm} \times 27 \mathrm{~cm} \times 21 \mathrm{~cm})$. Manually operated guillotine doors separated the chambers. The apparatus was modified with gaskets installed around the lids and an inlet for air or toluene vapor was installed at the top of both the black and white chambers. The number of entries and time spent in each of the chambers were recorded automatically by infrared photocells positioned $\sim 2$ inches above the floor of each chamber, and these data were used to calculate preference for each compartment.

The CPP paradigm consisted of three phases: preconditioning, conditioning, and testing phases. Preconditioning phase: Adolescent (P36) rats were first habituated for $5 \mathrm{~min}$ in the center gray chamber. After $5 \mathrm{~min}$ the guillotine doors were raised, and rats were allowed to explore all three chambers for $15 \mathrm{~min}$ to determine any preexisting bias of the apparatus. A baseline preference score was calculated during preconditioning by subtracting the time spent in the preferred chamber from the time spent in the nonpreferred chamber. Conditioning phase: Previous studies from other laboratories have shown that, in mice and rats, optimal CPP for toluene occurs after $6-12$ pairings at vapor concentrations between 2000 and $3000 \mathrm{ppm}$ of toluene (Funada et al., 2002; Gerasimov et al., 2003; Lee et al., 2004, 2006). To verify that the toluene vapor was in the optimal range, we monitored chamber toluene concentrations with a portable gas detector (DOD Technologies) during the exposure periods. Over a period of $12 \mathrm{~d}$, rats (P37-P48) were then exposed once per day to either air or toluene (3000 ppm) for $30 \mathrm{~min}$ while confined to either the black or white conditioning chamber. Toluene-exposed rats were paired with toluene in their least preferred conditioning chamber (determined during the preconditioning phase) alternated with air pairings in the other conditioning chamber. Air-exposed rats were paired with air in both conditioning chambers. Pairings alternated daily between chambers for both groups of rats. Testing phase: One day after the last conditioning day, rats (P49) habituated for $5 \mathrm{~min}$ in the center gray chamber and then were allowed to explore all three chambers for $15 \mathrm{~min}$ to determine side preference. A preference score was calculated by subtracting the time spent in the drug-paired chamber (identified in the preconditioning phase as the nonpreferred chamber) from the time spent in the air-paired chamber (identified in the preconditioning phase as the preferred chamber) (Lee et al., 2006). A subset of rats was retested 7 (P56) and $30 \mathrm{~d}$ (P79) later to determine whether the expression of CPP persisted. Clozapine-N-oxide (CNO) testing phase: A within-subjects, counterbalanced design was used to test how chemogenetic manipulation of mPFC-NAc pathways affected CPP. One day after the last conditioning day (P49), half of the animals were given an intraperitoneal injection of $10 \mathrm{mg} / \mathrm{kg} \mathrm{CNO}$ while the other half received the saline vehicle. At 30 minutes later, rats were habituated for $5 \mathrm{~min}$ in the center gray chamber and then were allowed to explore all three chambers for $15 \mathrm{~min}$ to determine side preference. The side preference test was repeated $2 \mathrm{~d}$ later with rats receiving the opposite injection to what they received on day 1 . For each test day, a preference score for each rat was calculated as the difference between the mean time spent in the drug-paired chamber minus the mean time spent in air-paired chamber.

Preparation of brain slices. After the last CPP test (P50, P57, or P80), rats were anesthetized with urethane $(3 \mathrm{mg} / \mathrm{kg}$, i.p.), and their forebrains were harvested and sectioned as previously described (Wayman and Woodward, 2017). Briefly, rats were perfused with an ice-cold sectioning solution, and the brains were then immediately harvested and coronal brain sections $(300 \mu \mathrm{m})$ containing the $\mathrm{mPFC}$ were sliced on a VT1000S vibratome (Leica Biosystems) in oxygenated $\left(95 \% \mathrm{O}_{2} / 5 \% \mathrm{CO}_{2}\right)$ sectioning solution and then transferred to a holding chamber containing normal aCSF (Beckley et al., 2013; Wayman and Woodward, 2017). Brain 

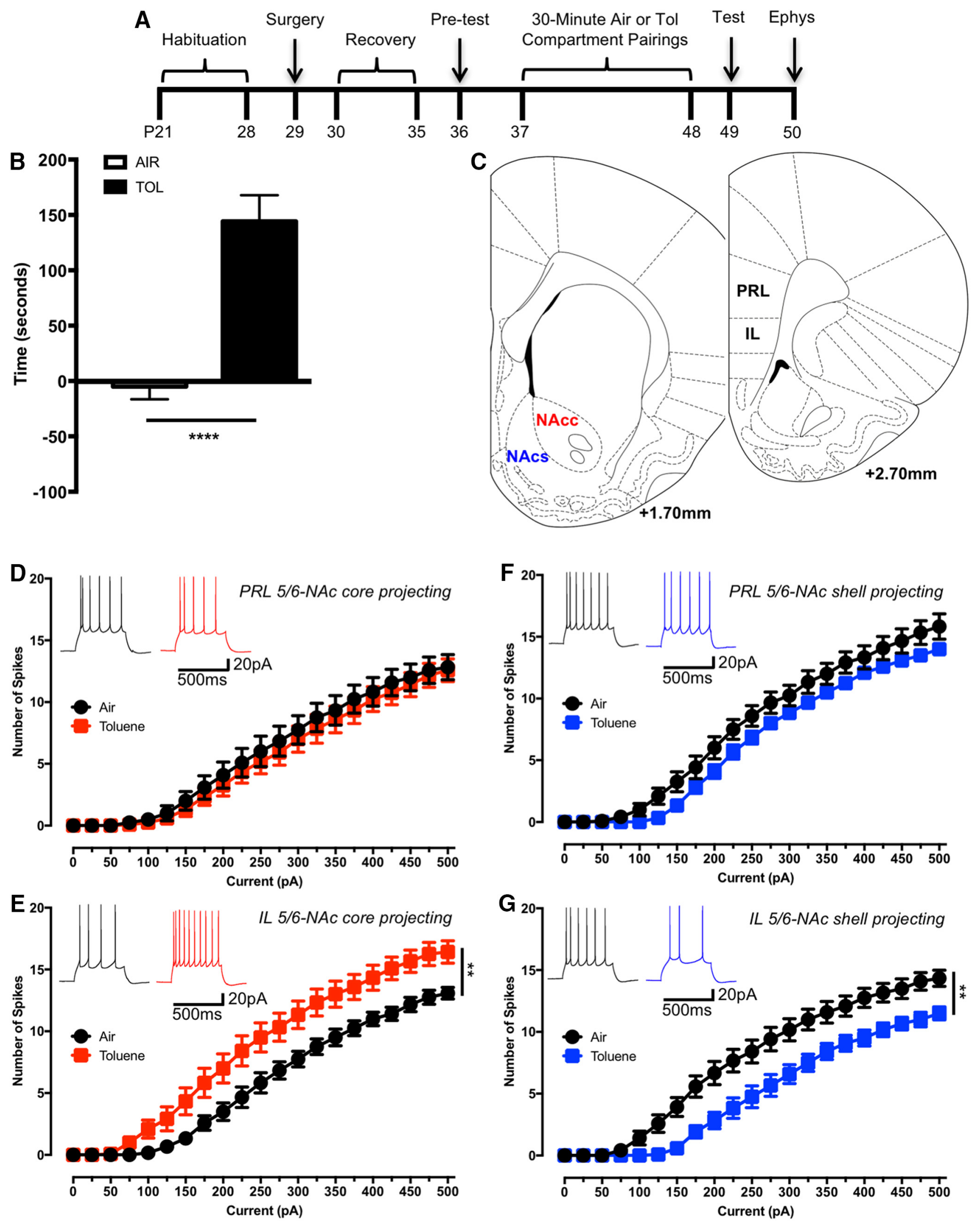

Figure 1. Toluene-induced CPP is associated with alterations in mPFC-NAc neuron excitability. $\boldsymbol{A}$, Experimental timeline showing alternating exposures to air or toluene vapor. $\boldsymbol{B}$, Tolueneexposed rats exhibit a significant preference for the drug-paired chamber (previously identified as the nonpreferred chamber) compared with rats that received air in both chambers during the conditioning paradigm. ${ }^{* * * *} p<0.0001$ (paired $t$ test). $C$, Representative image depicting the injection sites of the NAcc and NAcs as well as the recording sites of the PRL and IL prefrontal cortex (redrawn from Paxinos and Watson (2005)). D, Toluene-induced CPP does not alter evoked firing of PRL5/6-NAcc mPFC neurons ( $n=12$ ). $\boldsymbol{E}$, Toluene-induced (PP was associated with enhanced firing of IL5/6-NAcc mPFC neurons ( $n=12$ ). ${ }^{* *} p<0.01$ (two-way mixed ANOVA). $\boldsymbol{F}$, Toluene-induced CPP did not affect the firing of PRL5/6-NAcs mPFC (Figure legend continues.) 
slices were incubated at $34^{\circ} \mathrm{C}$ for $30 \mathrm{~min}$ and allowed to recover at room temperature for an additional $45 \mathrm{~min}$.

Ex vivo electrophysiology. As previously described (Wayman and Woodward, 2017), brain slices were transferred to the recording chamber and perfused with oxygenated and heated $\left(\sim 34^{\circ} \mathrm{C}\right)$ aCSF at a flow rate of $2 \mathrm{ml} / \mathrm{min}$. The temperature was maintained during the course of the recordings with in-line and bath heaters (Warner Instruments). A horizontal pipette puller (P-97 Sutter Instrument) was used to pull recording pipettes that were constructed from thin-walled borosilicate capillary glass tubing (I.D. $=1.17 \mathrm{~mm}$, O.D. $1.50 \mathrm{~mm}$; Warner Instruments). Pipettes were filled with an internal solution containing (in $\mathrm{mM}$ ) the following: $120 \mathrm{~K}$-gluconate, $10 \mathrm{HEPES}, 10 \mathrm{KCl}, 2 \mathrm{MgCl}_{2}, 2 \mathrm{Na}_{2} \mathrm{ATP}$, 0.3 NaGTP, 1 EGTA and 0.2\% biocytin; pH 7.35-7.45, and 285-295 $\mathrm{mOsm}$, and had resistances ranging from 3 to $5 \mathrm{M} \Omega$. Bead-labeled pyramidal neurons within layers $5 / 6$ of the PRL and IL subregions were visually identified using an FS2 microscope under epifluorescent conditions (Carl Zeiss) according to landmarks illustrated in a rat brain atlas (Paxinos and Watson, 2005). To achieve whole-cell access, light suction was applied after the formation of a gigaOhm seal to break through the cell membrane. Neurons with an access resistance $>20 \mathrm{mOhm}$ were not used for analysis. Recorded events were acquired with an Axon MultiClamp $700 \mathrm{~A}$ (Molecular Devices), digitized at a sampling rate of $10 \mathrm{kHz}$ (filtered at $4 \mathrm{kHz}$ ) with an Instrutech ITC-18 analog-digital converter (HEKA Instruments) controlled by AxographX software (Axograph Scientific) running on a Macintosh G4 computer (Apple). The resting membrane potential of all neurons was first recorded and then adjusted to $-70 \mathrm{mV}$ for electrophysiological assessments of excitability. Action potential firing was induced by a series of $500 \mathrm{~ms}$ current steps $(-400 \mathrm{pA}$ to $500 \mathrm{pA})$ incremented in $25 \mathrm{pA}$ steps. Recordings were analyzed offline for the number of spikes in response to each current step using AxographX software. In a subset of slice electrophysiology experiments, CNO (5-10 $\mu \mathrm{M}$; National Institutes of Health, Bethesda, MD) was added to the aCSF to activate $\mathrm{Gi}$ - or Gq-coupled DREADD receptors.

Statistical analysis. Data were analyzed using Prism Software version 7 (GraphPad Software) and SPSS (version 24; IBM). Preference scores and the number of entries into each chamber during the CPP paradigm of air and toluene conditioned rats were compared with $t$ tests and mixed ANOVA with Sidak's post hoc contrasts. Preference scores from the CNO studies were compared with mixed ANOVA and Sidak's post hoc contrasts. Current-voltage relationships were analyzed with mixed ANOVA and Sidak's post hoc contrasts. Current-voltage relationships were compared before and after application of $\mathrm{CNO}$ with repeated-measures ANOVA and Sidak's post hoc contrasts. Differences were considered significant with $\alpha<0.05$. Data are presented as mean and SEM. The number of neurons tested under each condition ranged from 8 to 12 .

\section{Results}

Toluene exposure induces $\mathrm{CPP}$ with projection- and subregion-specific alterations in the intrinsic excitability of mPFC pyramidal neurons

Following recovery from retrobead injection surgery, animals were first tested for any preexisting chamber bias (see timeline, Fig. 1A). As a group, rats expressed no bias for either chamber during preconditioning tests as indicated by the approximately equal times spent in both the black and white chambers (white: $266.8 \pm 10.4$ s; black: $268.1 \pm 12.7 \mathrm{~s} ; t_{(15)}=0.15, p=0.88$ ). However, each individual rat typically spent slightly more time on one side of the chamber than the other. We compared the preference scores of animals that were randomly assigned to be paired with air or toluene during the conditioning phase and found that there were no significant differences in preference scores between groups before the daily drug pairings (air:

(Figure legend continued.) neurons $(n=12)$. G Toluene-induced (PP was associated with reduced firing of IL5/6-NAcs mPFC neurons $(n=12) .{ }^{* *} p<0.01$ (two-way mixed ANOVA). Insets, All example traces obtained at the $250 \mathrm{pA}$ current injection step.
$-31.1 \pm 6.7 \mathrm{~s}$; toluene: $\left.-26.4 \pm 6.2 \mathrm{~s} ; t_{(14)}=0.52, p=0.61\right)$. After repeated pairings with toluene vapor, rats exhibited a significant place preference for the drug-paired chamber (identified during the preconditioning phase as the nonpreferred chamber) compared with the rats that received repeated pairings with air in both chambers $\left(t_{(14)}=5.69, p<0.0001\right.$; Fig. $\left.1 B\right)$. After CPP testing, rats were returned to their home cage and the following day and slices of the PRL and IL were prepared for recordings (representative sections illustrated in Fig. 1C). As shown in Figure $1 D$, the number of current-evoked action potentials from PRL5/6 neurons projecting to the NAc core (NAcc) was not different between toluene-exposed rats and those exposed to air (drug effect: $F_{(1,22)}=0.27, p=0.61$ ). In contrast, evoked firing of IL5/6-NAcc neurons was significantly enhanced in rats that expressed a toluene CPP (drug effect: $F_{(1,22)}=8.25, p=0.009$; Fig. $1 E)$. To determine whether the differential effect of toluene on mPFC firing was dependent on the NAc subregion, spiking was also measured in mPFC neurons from animals receiving retrobeads in the shell of the NAc (NAcs). Toluene treatment did not affect intrinsic excitability of PRL5/6-NAcs-projecting neurons (drug effect: $F_{(1,22)}=4.11, p=0.06$; Fig. $1 F$ ) but significantly reduced evoked firing of IL5/6-NAcs-projecting neurons (drug effect: $F_{(1,22)}=11.69, p=0.003$; Fig. $1 G$ ). These findings suggest that IL-NAc, but not PRL-NAc, connections within mPFC-NAc reward circuitry are modified during repeated exposures to toluene that produces CPP.

To determine whether toluene-induced CPP and changes in firing persist beyond $1 \mathrm{~d}, \mathrm{CPP}$ was assessed in another group of rats 1 and $7 \mathrm{~d}$ following air or toluene exposure and evoked firing was assessed $7 \mathrm{~d}$ after toluene exposure (see timeline, Fig. 2A). As a group, rats did not exhibit a preference for either conditioning chamber during the preconditioning phase indicated by the approximately equal times spent in both the black and white chambers (white: $288.8 \pm 12.6$ s; black: $298.4 \pm 14.6 \mathrm{~s} ; t_{(15)}=0.83, p=$ 0.42 ), although, again, individual animals typically spent slightly more time in one side versus the other. Animals were then assigned to either toluene or air pairings, and there were no significant differences in their preference scores between these groups (air: $-25.9 \pm 6.1 \mathrm{~s}$; toluene: $-45.4 \pm 13.1 \mathrm{~s} ; t_{(14)}=1.34, p=$ 0.20 ). Daily pairings during the conditioning phase produced a significant CPP in the toluene-exposed group compared with air only $\left(F_{(1,14)}=35.49, p<0.0001\right)$, but there was no effect of withdrawal $\left(F_{(1,14)}=0.42, p=0.53\right)$ or an interaction between drug exposure and withdrawal $\left(F_{(1,14)}=0.53, p=0.48\right.$; Fig. $\left.2 B\right)$. Post hoc analysis also revealed that preference scores were significantly different between air- and toluene-exposed rats on withdrawal day $1(\mathrm{WD} 1)(p=0.0004)$, and this preference persisted to at least withdrawal day 7 (WD7) $(p=0.0079 ;$ Fig. $2 B)$. Similar to the neurophysiological changes observed $1 \mathrm{~d}$ after toluene exposure, PRL5/6-NAcc pyramidal neurons showed no change in firing at $7 \mathrm{~d}$ after exposure (drug effect: $F_{(1,22)}=0.02, p=0.88$; Fig. 2C) compared with air controls. However, evoked firing of IL5/6-NAcc neurons was significantly enhanced in toluene CPP rats $7 \mathrm{~d}$ after the last exposure (drug effect: $F_{(1,22)}=8.27, p=$ 0.009; Fig. $2 D$ ). There were no differences in firing of PRL5/6NAcs pyramidal neurons following a $7 \mathrm{~d}$ recovery from toluene exposure (drug effect: $F_{(1,22)}=0.17, p=0.68$, Fig. $2 E$ ), but evoked firing of IL5/6-NAcs-projecting neurons from toluene $\mathrm{CPP}$ rats was still reduced $7 \mathrm{~d}$ after the last exposure (drug effect: $F_{(1,22)}=8.01, p=0.01$; Fig. $\left.2 F\right)$. These findings indicate that repeated exposures to binge-like concentrations of toluene produce a change in the excitability of IL-NAc neurons that persists for at least 1 week. 

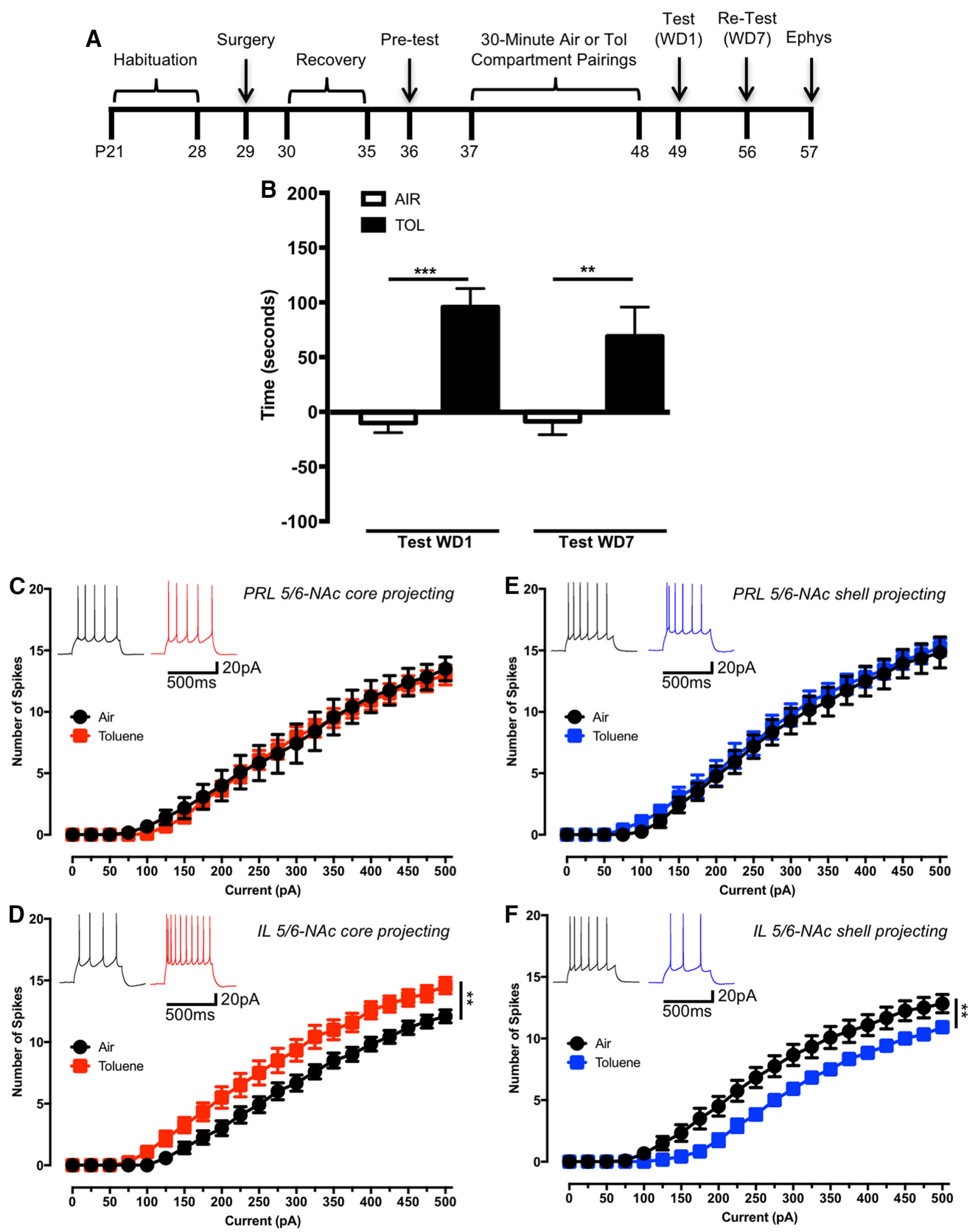

Figure 2. Toluene-induced CPP and underlying changes in mPFC-NAcneuronal excitability persistfor at least $7 \mathrm{~d}$. $\boldsymbol{A}$, Experimental timeline showingalternating exposures to air or toluenevapor. $\boldsymbol{B}$, Preference scores were significantly different between air- and toluene-exposed rats on WD1 $\left.{ }^{* * *} p<0.001\right)$, and this preference persisted to at least WD7 $\left({ }^{* *} p<0.01\right.$, two-way mixed ANOVA Sidak's post hoc). C, Toluene-induced CPP did not alter the firing of PRL5/6-NAcc mPFC neurons $(n=12)$. D, Toluene-induced CPP was associated with enhanced firing of IL5/6-NAccmPFC neurons that persist for $7 \mathrm{~d}$ after the last exposure $\left(n=12\right.$; ${ }^{* *} p<0.01$, two-way mixed ANOVA). $\boldsymbol{E}$, Toluene-induced CPP did not affect the firing of PRL5/6-NAcs mPFC neurons $(n=12)$. $\boldsymbol{F}$, Toluene-induced CPP was associated with reduced firing of IL5/6-NAcs mPFC neurons that persist for $7 \mathrm{~d}$ after the last exposure $\left(n=12 ;{ }^{* *} p<0.01\right.$, two-way mixed ANOVA). Insets, All representative traces obtained at the $250 \mathrm{pA}$ current injection step. 

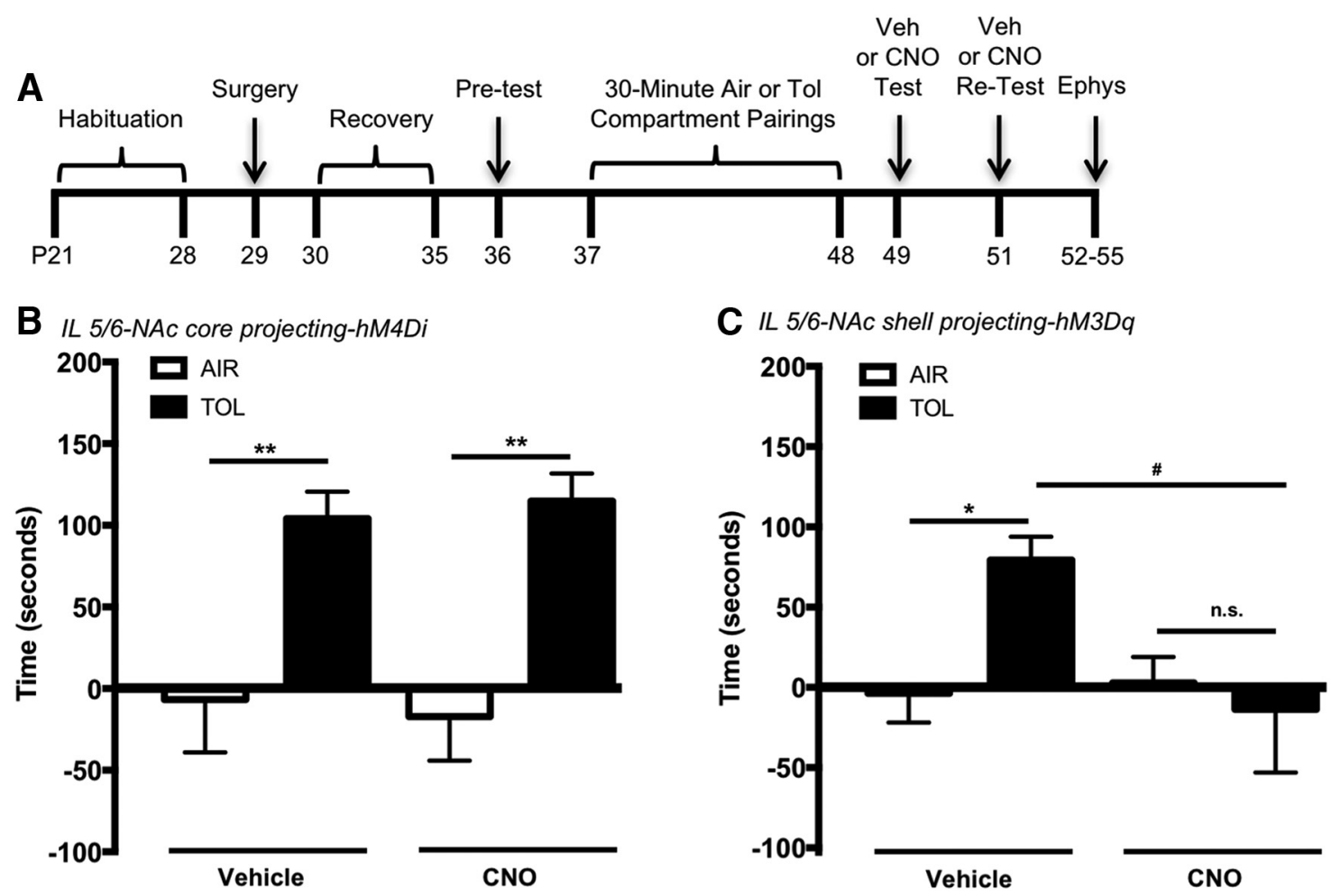

Figure 3. Chemogentic modification of IL5/6-NAcs activity prevents expression of toluene-induced CPP.A, Experimental timeline showing alternating exposures to air or toluene vapor and CPP testing. B, IL5/6-NAcc-hM4Di rats exhibited a clear preference for the toluene-paired chamber following injection of either the saline vehicle ${ }^{* *} p<0.01$, two-way mixed ANOVA Sidak's post hoc) or CNO (** $p<0.01$, two-way mixed ANOVA Sidak's post hoc). C, Toluene-exposed IL5/6-NAcs-hM3Dq rats exhibited a preference for the toluene-paired chamber following injection of saline ( ${ }^{*} p<$ 0.05, two-way mixed ANOVA Sidak's post hoc) but not CNO ( ${ }^{\text {n.s. }} p>0.05$, two-way mixed ANOVA Sidak's post hoc). (PP for the drug-paired chamber in toluene-exposed IL5/6-NAcs-hM3Dq during saline injection was blocked when they were given CNO. ${ }^{\#}<0.05$ (two-way mixed ANOVA Sidak's post hoc).

\section{Selective manipulation of IL-NAc physiology attenuates toluene-induced CPP}

If the expression of toluene CPP requires changes in IL5/6-NAc neuron activity, then reversing these changes should block the preference for the toluene-paired side. To test this, CPP was assessed in rats bilaterally injected in the IL cortex with an AAV virus encoding Cre-dependent DREADDs (hM3Dq or hM4Di) and a retrograde CAV2-Cre virus injected bilaterally into either the NAcc or NAcs. Rats were tested for CPP 1 and $3 \mathrm{~d}$ after the final air or toluene vapor pairing and received either saline or $\mathrm{CNO}$ before testing using a within-subjects, counterbalanced design (Fig. 3A).

As a group, rats expressing the inhibitory hM4Di DREADD in IL5/6-NAcc-projecting neurons had no side preference during preconditioning tests (white: $269.5 \pm 14.8 \mathrm{~s}$; black: $261.7 \pm$ $17.5 \mathrm{~s} ; t_{(15)}=0.52, p=0.61$ ), and no significant difference in preference score was observed between rats to be paired with air and those to be paired with toluene (air: $-46.9 \pm 9.4 \mathrm{~s}$; toluene: $-55.8 \pm 12.5 \mathrm{~s} ; t_{(14)}=0.57, p=0.58$ ). Following drug pairing, ANOVA revealed a significant main effect of toluene exposure $\left(F_{(1,14)}=17.53, p=0.0009\right)$, but there was no main effect of CNO $\left(F_{(1,14)}=0.0003, p=0.99\right)$ or an interaction between drug exposure and $\mathrm{CNO}$ treatment $\left(F_{(1,14)}=0.33, p=0.57\right.$; Fig. $\left.3 B\right)$. Post hoc analysis revealed that IL5/6-NAcc-hM4Di rats exhibited a clear preference for the toluene-paired chamber following injection of either the saline vehicle $(p=0.0061)$ or $\mathrm{CNO}(p=0.0012$; Fig. 3B).

As a group, rats expressing the excitatory hM3Dq DREADD had no side preference during preconditioning tests (white: $291.2 \pm 14.4$ s; black: $\left.301.0 \pm 14.1 \mathrm{~s} ; t_{(15)}=0.49, p=0.63\right)$, and no significant difference in preference score was observed between rats that to be paired with air and those to be paired with toluene prior (air: $-44.8 \pm 9.1 \mathrm{~s}$; toluene: $-85.3 \pm 18.6 \mathrm{~s} ; t_{(14)}=$ 1.96, $p=0.07)$. After daily pairings during the conditioning phase, there was no significant main effect of drug exposure between air- and toluene-exposed rats $\left(F_{(1,14)}=1.60, p=0.23\right)$ or $\mathrm{CNO}\left(F_{(1,14)}=3.86, p=0.07\right)$, although there was a significant interaction between drug exposure and $\mathrm{CNO}$ treatment $\left(F_{(1,14)}=\right.$ 5.09, $p=0.04$; Fig. $3 C$ ). Post hoc analysis revealed that tolueneexposed IL5/6-NAcs-hM3Dq rats given saline exhibited a significant preference for the toluene-paired chamber $(p=0.04)$; however, animals given $\mathrm{CNO}$ did not exhibit CPP for the toluene paired chamber $(p=0.87)$. Post hoc analysis between toluene-exposed IL5/ 6-NAcs-hM3Dq that received saline and those that received CNO revealed that $\mathrm{CPP}$ was blocked in rats when they were given $\mathrm{CNO}$ ( $p=0.02$; Fig. $3 C)$.

To further demonstrate that the reduction in CPP of IL5/6NAcs-hM3Dq rats was due to activation of the DREADD receptor and not to off-target effects of $\mathrm{CNO}$ or its metabolites, a separate group of rats received a bilateral injection of an AAV encoding a Cre-dependent mCherry reporter into the IL5/6 and CAV2-Cre in the NAcs. After recovery, animals were run through the toluene CPP paradigm described previously. As a group, IL5/ 6-NAcs-mCherry rats showed no side preference during preconditioning tests (white: $304.9 \pm 22.2 \mathrm{~s}$; black: $287.7 \pm 28.6 \mathrm{~s} ; t_{(7)}=$ $0.60, p=0.56$ ), and the preference score before the drug pairing was similar to the other groups tested $(-59.0 \pm 18.8)$. Following the conditioning phase, there was no difference in the preference score for the toluene-paired chamber between when the animals 

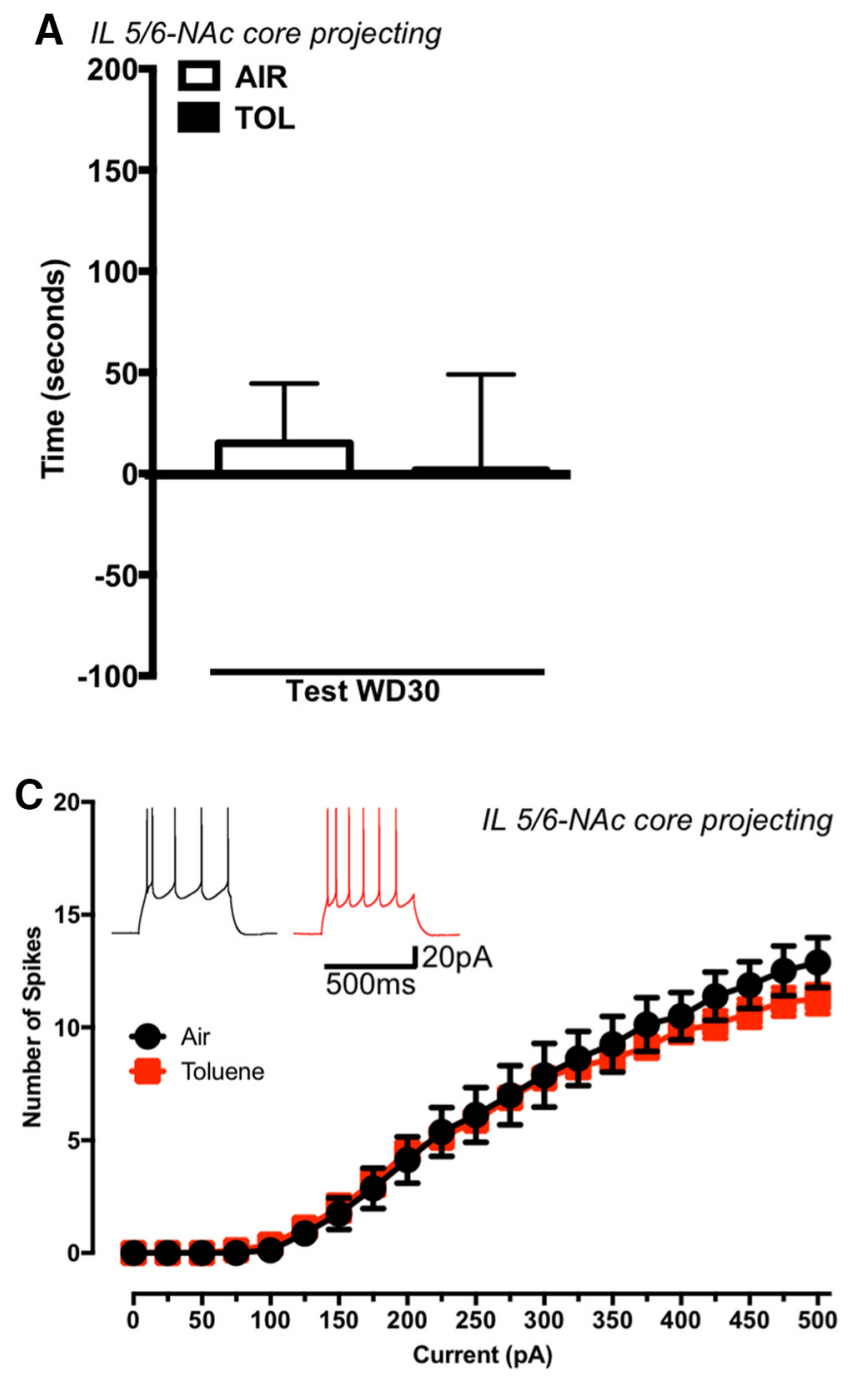
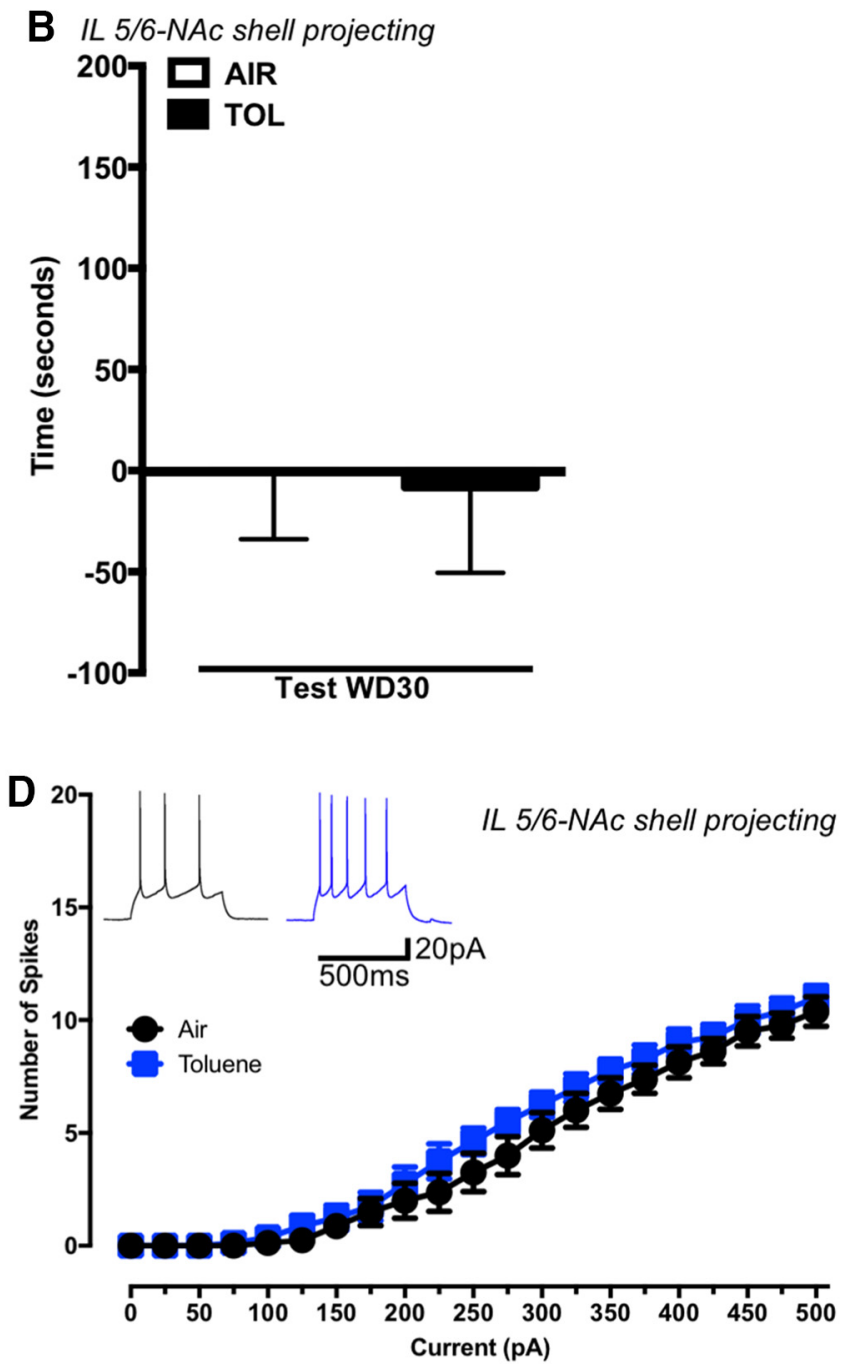

Figure 4. Toluene-induced CPP and altered excitability of IL-NAc-projecting neurons is no longer present $30 \mathrm{~d}$ after the last conditioning day. No differences in preference scores were observed between rats paired with toluene or air when tested after $30 \mathrm{~d}$ of withdrawal. $\boldsymbol{A}, \mathrm{IL} 5 / 6-\mathrm{NAcchM}$ 4Dirats. $\boldsymbol{B}, \mathrm{IL} 5 / 6-\mathrm{NAcs}$ hM3Dq rats. $\boldsymbol{C}$, No differences in evoked firing of IL5/6-NAcc mPFC neurons ( $n=$ 8) between air- and toluene-exposed animals $30 \mathrm{~d}$ after the last pairing session. $\boldsymbol{D}$, No differences in evoked firing of IL5/6-NAcs mPFC neurons ( $n=8$ ) between air- and toluene-exposed animals $30 \mathrm{~d}$ after the last pairing session. Insets, All representative traces obtained at the $250 \mathrm{pA}$ current injection step.

received vehicle and $\mathrm{CNO}$ injections (vehicle: $84.2 \pm 14.0 \mathrm{~s}$; CNO: $\left.79.7 \pm 12.5 s ; t_{(7)}=0.24, p=0.82\right)$.

To determine whether the reduction in CPP observed following $\mathrm{CNO}$ injection was due to nonspecific $\mathrm{CNO}$-induced changes in exploratory behavior (MacLaren et al., 2016), the number of chamber entries for each animal following injection of saline or $\mathrm{CNO}$ were compared. There was no difference in chamber entries between air-exposed hM4Di DREADD-expressing rats following an injection of saline vehicle $(109.3 \pm 11.6)$ or CNO $(103.5 \pm$ 10.4; CNO effect: $\left.t_{(7)}=0.65, p=0.54\right)$. Likewise, chamber entries of toluene-exposed hM4Di DREADD rats were similar whether animals were injected with saline vehicle $(128.9 \pm 18.0)$ or $\mathrm{CNO}$ (116.5 \pm 13.9 ; CNO effect: $t_{(7)}=0.96, p=0.37$ ), and comparable findings were found for air-exposed hM3Dq rats (saline vehicle, $149.6 \pm 7.2$; CNO, $132.9 \pm 14.0$; CNO effect: $t_{(7)}=1.32, p=$ 0.22 ) and those paired with toluene (saline vehicle, $129.3 \pm 6.3$; CNO, $140.1 \pm 9.8$; CNO effect: $t_{(7)}=1.34, p=0.22$ ). Together, these findings suggest that CNO itself did not affect exploratory behavior and that the reduction in the time spent in the unpaired chamber was not a consequence of reduced locomotor activity.
Toluene-induced CPP is not permanent

To assess whether repeated exposures to toluene produces irreversible changes in behavior and electrophysiology of IL5/6-NAc neurons, we measured toluene-induced CPP and evoked firing in the same DREADD-expressing rats used in the CNO studies $30 \mathrm{~d}$ after the last pairing session. In this experiment, rats were not injected with saline vehicle or CNO before the CPP test. Following $30 \mathrm{~d}$ of withdrawal, there were no differences in preference scores between toluene and air-paired rats in either the IL5/6NAcc $\left(t_{(14)}=0.24, p=0.81\right.$; Fig. $\left.4 A\right)$ or IL5/6-NAcs DREADDexpressing rats $\left(t_{(14)}=0.15, p=0.88\right.$; Fig. $\left.4 B\right)$. Similarly, the toluene-induced change in evoked firing of IL5/6-NAc neurons observed at 1 and $7 \mathrm{~d}$ (Figs. 1,2) was no longer present $30 \mathrm{~d}$ after the last pairing session (IL5/6-NAcc drug effect: $F_{(1,14)}=0.18$, $p=0.68$, Fig. $4 C$; IL5/6-NAcs drug effect: $F_{(1,14)}=1.04, p=0.33$, Figure 4D).

\section{Both DREADDs were expressed and functional}

DREADD expression and function were verified using the animals tested for CPP and evoked firing $30 \mathrm{~d}$ after the last pairing 
A
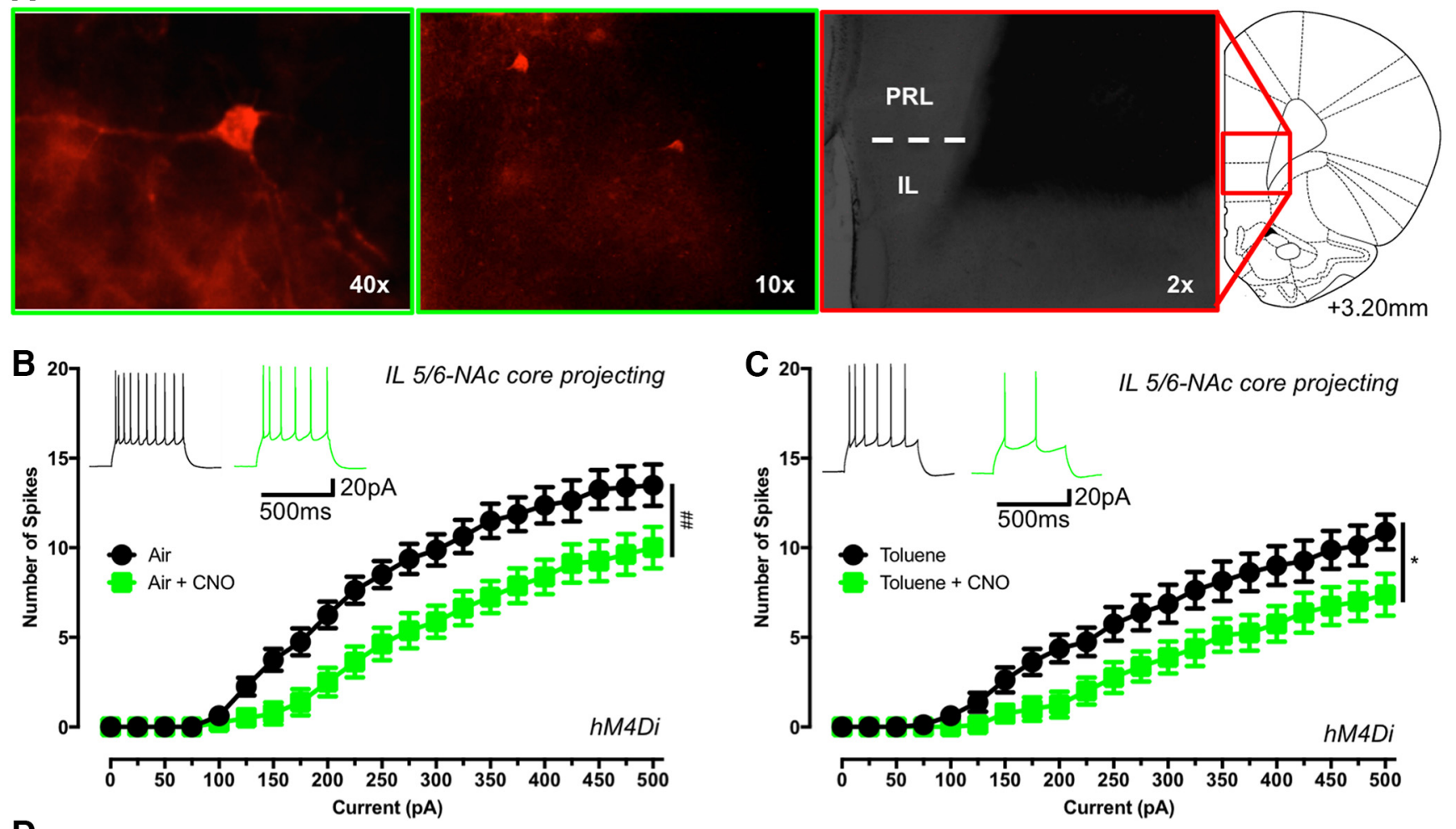

D
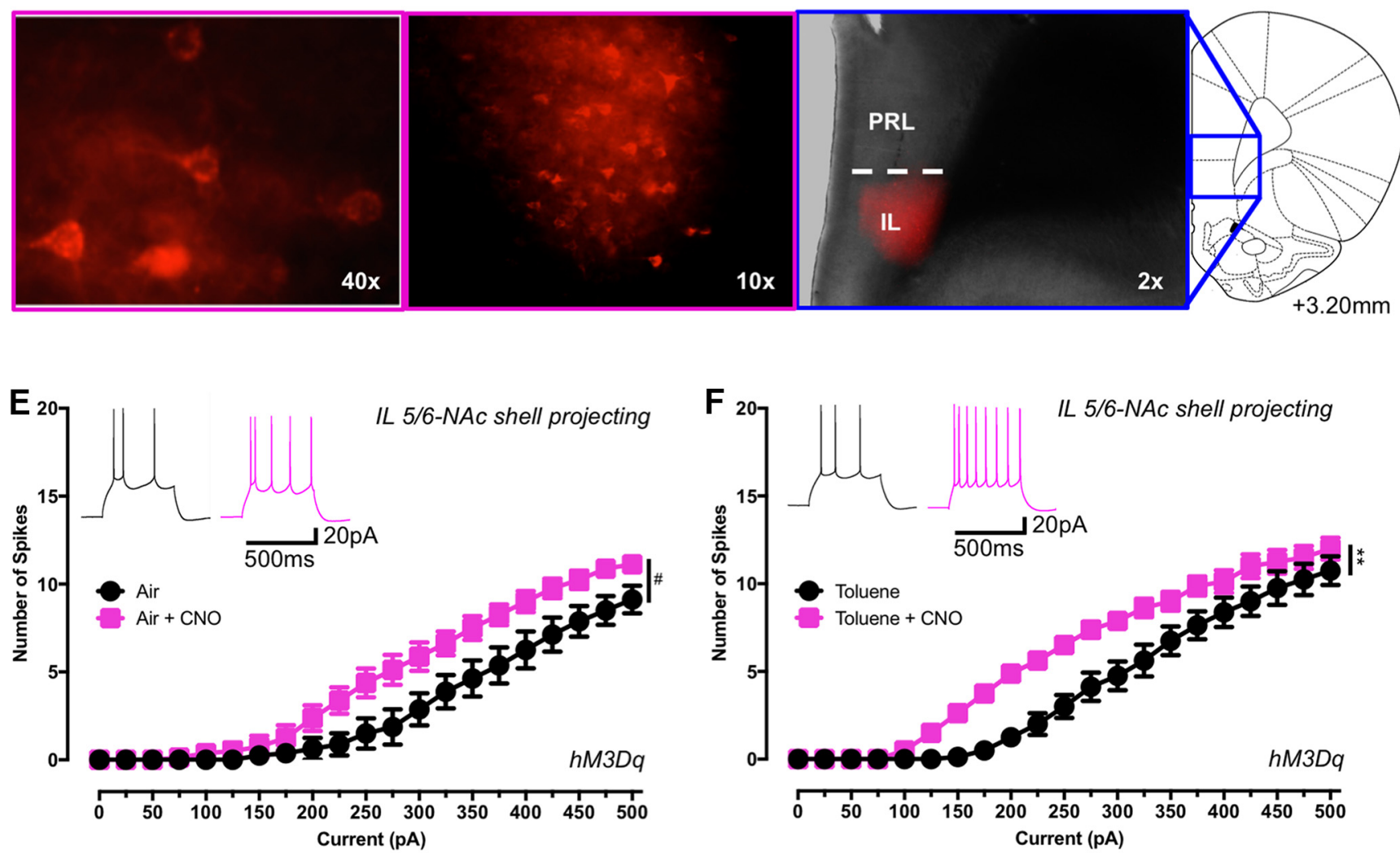

Figure 5. Validation of expression and function of Gi- and Gq-DREADDs. A, Representative images and atlas drawings showing location and expression of hM4Di Gi-DREADDs. Atlas diagrams of cortical rat brain slices (redrawn from Paxinos and Watson, 2005) show extent of hM4Di Gi-DREADD labeling in IL5/6-NAcc pyramidal neurons used for recording. Images show IL5/6-NAcc pyramidal neurons expressing hM4DiGi-DREADD labeling at $2 \times$ (right), $10 \times$ (middle), and $40 \times$ (left). $\boldsymbol{B}$, Firing of IL5/6-NAcc neurons $(n=8)$ in mPFC slices from air-exposed hM4Di-infected rats is inhibited by bath application of $5 \mu \mathrm{M}$ CNO. ${ }^{\# \#} p<0.01$ (two-way repeated-measures ANOVA). C, Firing of IL5/6-NAcc neurons $(n=8)$ in mPFC slices from toluene-exposed hM4Di-infected rats is inhibited by bath application of $5 \mu \mathrm{M} C N 0 .{ }^{*} p<0.05$ (two-way repeated-measures ANOVA). D, Representative images and atlas drawings showing location and expression of hM3Dq Gq-DREADDs. Atlas diagrams of cortical rat brain slices (redrawn from Paxinos and Watson, 2005) show extent of hM3Dq Gq-DREADD labeling in IL5/6-NAcs pyramidal neurons used for recording. Images show IL5/6-NAcs pyramidal neurons expressing hM3Dq Gq-DREADD labeling at $2 \times$ (right), 10× (middle), and 40× (left). E, Firing of IL5/6-NAcs neurons ( $n=8$ ) (Figure legend continues.) 
session. As shown in Figure $5 \mathrm{~A}$ and consistent with our previous retrobead labeling study (Wayman and Woodward, 2017), there was sparse DREADD labeling of IL5/6-NAcc-projecting pyramidal neurons. Spiking in these hM4Di DREADD-expressing ILNAcc neurons was reduced during bath application of $5 \mu \mathrm{M}$ $\mathrm{CNO}$, and this was similar in neurons from both air-exposed rats (CNO effect: $F_{(1,14)}=10.86, p=0.005$; Fig. $\left.5 B\right)$ and tolueneexposed rats (CNO effect: $F_{(1,14)}=25.95, p=0.03$; Fig. $5 C$ ). There was a high density of labeled IL5/6-NAcs-projecting pyramidal neurons in rats expressing the hM3Dq DREADD (Fig. 5D), and bath application of $10 \mu \mathrm{M}$ CNO significantly enhanced firing of IL-NAcs-projecting neurons from air-exposed rats (CNO effect: $F_{(1,14)}=5.90, p=0.03$; Fig. $\left.5 E\right)$ and toluene-exposed rats (CNO effect: $F_{(1,14)}=10.98, p=0.005$; Fig. $\left.5 F\right)$.

\section{Discussion}

The major findings of the current study are that repeated exposures of rats to $\sim 3000 \mathrm{ppm}$ toluene vapor produces reliable CPP and generates projection- and subregion-specific changes in the excitability of NAc-projecting mPFC pyramidal neurons. Specifically, pyramidal neurons arising from the IL cortex showed changes in evoked firing that varied depending on whether they projected to the NAcc (increased firing) or the NAcs (decreased firing). The toluene-induced changes in evoked firing and CPP were apparent within $1 \mathrm{~d}$ following the last toluene vapor exposure, persisted for at least $7 \mathrm{~d}$, and fully recovered after $30 \mathrm{~d}$. Moreover, the expression of toluene CPP was prevented by GqDREADD excitation of IL5/6-NAcs neurons but not by GiDREADD inhibition of IL5/6-NAcc activity. These findings suggest that a selective corticolimbic circuitry is involved in the expression of a measure of toluene reward following repeated binge exposures of adolescent rats to toluene.

\section{Toluene-induced alterations to reward circuitry}

Both PRL and IL projections to the NAcc and NAcs have been shown to play a major role in the behavioral responses (i.e., extinction and reinstatement of drug-seeking) to drugs of abuse, such as cocaine, methamphetamine, ecstasy, and alcohol (Peters et al., 2009; Rocha and Kalivas, 2010; Ball and Slane, 2012; Willcocks and McNally, 2013). For psychostimulants, such as cocaine, IL-NAcs neurons are involved in reinstatement to cueinduced drug-seeking, where increasing activity of these neurons via Gq-DREADDs reduces cue-induced drug-seeking after extinction (Augur et al., 2016). In contrast, heroin-seeking is reduced when the ventral mPFC is inhibited (Bossert et al., 2012). It should be noted that results from studies using CPP to model reward conflicts with those from self-administration studies in terms of vmPFC function in opiate-exposed animals. For instance, inactivation of the vmPFC elicits a reinstatement of CPP for heroin after extinction (Ovari and Leri, 2008). Our results with toluene and CPP support the idea that hypoactivity of ILNAcs neurons is associated with a preference for the chamber associated with the drug. Together, these findings support the idea that drug-seeking behavior is allowed to proceed when the IL-NAcs connections are weakened.

\section{$\leftarrow$}

(Figure legend continued.) in mPFC slices from air-exposed hM3Dq-infected rats exhibit enhanced firing following application of $10 \mu \mathrm{M} C \mathrm{NN} 0 .{ }^{\#} p<0.05$ (two-way repeated-measures ANOVA). $\boldsymbol{F}$, Firing of IL5/6-NAcs neurons $(n=8)$ in mPFC slices from toluene-exposed hM3Dqinfected rats exhibit enhanced firing following application of $10 \mu \mathrm{M}$ CNO. ${ }^{* *} p<0.01$ (two-way repeated-measures ANOVA). Insets, All representative traces obtained at the $250 \mathrm{pA}$ current injection step.
We have previously shown that a single binge exposure to toluene produces alterations in mPFC neuron excitability that varies on a subregion/layer/projection target manner (Wayman and Woodward, 2017). To expand these findings, we investigated whether evoked firing of $\mathrm{mPFC}$ pyramidal neurons projecting to the NAc was also affected in animals expressing CPP for toluene. Consistent with the previous study, toluene-induced CPP was associated with increased firing of IL5/6-NAcc pyramidal neurons, and decreased excitability of IL5/6-NAcs pyramidal neurons. Interestingly, an additional prominent effect of a single binge exposure to toluene is a significant reduction in evoked spiking of PRL5/6 pyramidal neuron that project to the NAcc (Wayman and Woodward, 2017). This change was not observed in the current study where animals were repeatedly exposed to toluene. Although the lack of effect of repeated toluene exposures on PRL activity could be due the use of different concentrations between the studies ( $\sim 3000 \mathrm{ppm}$ vs $10,500 \mathrm{ppm}$ ), it is also possible that animals may acclimatize to the stress associated with toluene vapor that has known irritating properties. Reduced PRL activity has been shown to be a consequence in animals exhibiting physical or psychological stress (Vialou et al., 2014), and stimulation of PRL neurons can reverse these deficits (Covington et al., 2010; Vialou et al., 2014). In addition, whereas changes in firing of mPFC-NAc pyramidal neurons from rats repeatedly conditioned with $\sim 3000 \mathrm{ppm}$ toluene persisted for at least $7 \mathrm{~d}$, those produced by a single binge exposure recovered within this time. While consistent with the idea that chronic drug exposure can produce long-lasting changes in neural circuitry, these results also suggest that different patterns of inhalant abuse (e.g., occasional vs intermittent vs chronic) may target unique ensembles of neurons within discrete mPFC subregions and contribute to individual differences in drug-seeking and relapse behavior.

\section{Toluene-induced place preference}

Mounting evidence suggests that the development of inhalant abuse involves drug-induced modifications to the physiology of the mesocorticolimbic reward circuitry, similar to that observed for other drugs of abuse. Although exposure to toluene alters neuronal excitability across a wide variety of concentrations, CPP for toluene requires concentrations high enough to be reinforcing, but not so high that animals are sedated and unable to learn the drug/environment association. Previous studies from other laboratories have shown that, in mice and rats, optimal CPP for toluene occurs at vapor concentrations between 2000 and 3000 ppm of toluene (Funada et al., 2002; Gerasimov et al., 2003; Lee et al., 2004, 2006) and preference diminishes as concentrations approach 5000 ppm (Gerasimov et al., 2003; Lee et al., 2006). Interestingly, exposure to similar concentrations (3000-7000 ppm) of toluene produces significant increases in extracellular dopamine in the mPFC and accumbens (Gerasimov et al., 2002; Koga et al., 2007), consistent with that produced by other drugs of abuse, such as cocaine, that also modify this reward circuitry (Gerasimov et al., 2002). Prior studies examining toluene-induced CPP also reveal that 6-14 pairings are needed to induce a reliable preference for toluene, with more pairings yielding a stronger preference. The findings of the present study are consistent with these reports as CPP for toluene was obtained following 6 pairings with $3000 \mathrm{ppm}$ toluene, and these animals showed selective alterations in excitability of mPFC-NAc-projecting pyramidal neurons. The importance of these changes was validated by the observation that DREADD-induced manipulation of IL5/6NAcs neurons blocked the expression of CPP. 


\section{Controlling for potential off-target effects of CNO}

Although CNO activation of DREADDs has been used extensively to analyze circuit-specific control of various behaviors (Roth, 2016), findings from a recent study suggest that CNO metabolites, including clozapine, produce off-target effects, such as locomotor deficits, that may confound interpretation of the data (MacLaren et al., 2016; Gomez et al., 2017). This is of particular concern when studying drugs of abuse, such as psychostimulants, where enhanced locomotor activity is a notable effect of the drug. In the present study, no deficits in locomotor activity following $\mathrm{CNO}$ administration were found as indicated by a lack of difference between $\mathrm{CNO}$ - and saline-injected animals in the total number of chamber entries animals made during the CPP test. Furthermore, for the present study, $\mathrm{CNO}$ was given $30 \mathrm{~min}$ before the $20 \mathrm{~min}$ CPP test, a total time well short of the $2-3 \mathrm{~h}$ time point in which locomotor deficits from systemic $\mathrm{CNO}$ injections are reported to occur (Gomez et al., 2017). Finally, the block of CPP expression by $\mathrm{CNO}$ observed in the present study was restricted to animals expressing the hM3Dq DREADD in IL5/6 NAcs-projecting neurons as CNO had no effect on toluene CPP hM4Di DREADD or mCherry reporter-expressing rats. Together, these findings suggest that it is highly unlikely that a non-DREADD mechanism was involved in CNO's effect on toluene CPP.

In conclusion, the present study revealed that repeated pairings with toluene vapor induces a CPP that is mediated in part by projection- and subregion-specific alterations in the intrinsic excitability of NAc-projecting mPFC pyramidal neurons. These findings add to the growing appreciation that volatile solvents, like other more well-studied drugs of abuse, engage corticolimbic circuitry to produce their effects.

\section{References}

Augur IF, Wyckoff AR, Aston-Jones G, Kalivas PW, Peters J (2016) Chemogenetic activation of an extinction neural circuit reduces cue-induced reinstatement of cocaine seeking. J Neurosci 36:10174-10180. CrossRef Medline

Ball KT, Slane M (2012) Differential involvement of prelimbic and infralimbic medial prefrontal cortex in discrete cue-induced reinstatement of 3,4-methylenedioxymethamphetamine (MDMA; ecstasy) seeking in rats. Psychopharmacology (Berl) 224:377-385. CrossRef Medline

Beckley JT, Evins CE, Fedarovich H, Gilstrap MJ, Woodward JJ (2013) Medial prefrontal cortex inversely regulates toluene-induced changes in markers of synaptic plasticity of mesolimbic dopamine neurons. J Neurosci 33:804-813. CrossRef Medline

Block AE, Dhanji H, Thompson-Tardif SF, Floresco SB (2007) Thalamicprefrontal cortical-ventral striatal circuitry mediates dissociable components of strategy set shifting. Cereb Cortex 17:1625-1636. CrossRef Medline

Blokhina EA, Dravolina OA, Bespalov AY, Balster RL, Zvartau EE (2004) Intravenous self-administration of abused solvents and anesthetics in mice. Eur J Pharmacol 485:211-218. CrossRef Medline

Bossert JM, Stern AL, Theberge FR, Marchant NJ, Wang HL, Morales M, Shaham Y (2012) Role of projections from ventral medial prefrontal cortex to nucleus accumbens shell in context-induced reinstatement of heroin seeking. J Neurosci 32:4982-4991. CrossRef Medline

Burgos-Robles A, Bravo-Rivera H, Quirk GJ (2013) Prelimbic and infralimbic neurons signal distinct aspects of appetitive instrumental behavior. PLoS One 8:e57575. CrossRef Medline

Covington HE 3rd, Lobo MK, Maze I, Vialou V, Hyman JM, Zaman S, LaPlant Q, Mouzon E, Ghose S, Tamminga CA, Neve RL, Deisseroth K, Nestler EJ (2010) Antidepressant effect of optogenetic stimulation of the medial prefrontal cortex. J Neurosci 30:16082-16090. CrossRef Medline

Crews F, He J, Hodge C (2007) Adolescent cortical development: a critical period of vulnerability for addiction. Pharmacol Biochem Behav 86:189199. CrossRef Medline

Funada M, Sato M, Makino Y, Wada K (2002) Evaluation of rewarding effect of toluene by the conditioned place preference procedure in mice. Brain Res Brain Res Protoc 10:47-54. CrossRef Medline

Gerasimov MR, Schiffer WK, Marstellar D, Ferrieri R, Alexoff D, Dewey SL (2002) Toluene inhalation produces regionally specific changes in extracellular dopamine. Drug Alcohol Depend 65:243-251. CrossRef Medline Gerasimov MR, Collier L, Ferrieri A, Alexoff D, Lee D, Gifford AN, Balster RL (2003) Toluene inhalation produces a conditioned place preference in rats. Eur J Pharmacol 477:45-52. CrossRef Medline

Gomez JL, Bonaventura J, Lesniak W, Mathews WB, Sysa-Shah P, Rodriguez LA, Ellis RJ, Richie CT, Harvey BK, Dannals RF, Pomper MG, Bonci A, Michaelides M (2017) Chemogenetics revealed: DREADD occupancy and activation via converted clozapine. Science 357:503-507. CrossRef Medline

Koga Y, Higashi S, Kawahara H, Ohsumi T (2007) Toluene inhalation increases extracellular noradrenaline and dopamine in the medial prefrontal cortex and nucleus accumbens in freely-moving rats. J Kyushu Dent Soc 61:39-54. CrossRef

Lee DE, Schiffer WK, Dewey SL (2004) Gamma-vinyl GABA (vigabatrin) blocks the expression of toluene-induced conditioned place preference (CPP). Synapse 54:183-185. CrossRef Medline

Lee DE, Gerasimov MR, Schiffer WK, Gifford AN (2006) Concentrationdependent conditioned place preference to inhaled toluene vapors in rats. Drug Alcohol Depend 85:87-90. CrossRef Medline

Lüscher C, Malenka RC (2011) Drug-evoked synaptic plasticity in addiction: from molecular changes to circuit remodeling. Neuron 69:650-663. CrossRef Medline

MacLaren DA, Browne RW, Shaw JK, Krishnan Radhakrishnan S, Khare P, España RA, Clark SD (2016) Clozapine N-oxide administration produces behavioral effects in Long-Evans rats: implications for designing DREADD experiments. eNeuro 3:ENEURO.0219-16.2016. CrossRef Medline

Nimitvilai S, You C, Arora DS, McElvain MA, Vandegrift BJ, Brodie MS, Woodward JJ (2016) Differential effects of toluene and ethanol on dopaminergic neurons of the ventral tegmental area. Front Neurosci 10:434. CrossRef Medline

Ovari J, Leri F (2008) Inactivation of the ventromedial prefrontal cortex mimics re-emergence of heroin seeking caused by heroin reconditioning. Neurosci Lett 444:52-55. CrossRef Medline

Paxinos G, Watson C (2005) The rat brain in stereotaxic coordinates: the new Coronal set, Ed 5. Cambridge, MA: Academic.

Peters J, Kalivas PW, Quirk GJ (2009) Extinction circuits for fear and addiction overlap in prefrontal cortex. Learn Mem 16:279-288. CrossRef Medline

Riegel AC, Zapata A, Shippenberg TS, French ED (2007) The abused inhalant toluene increases dopamine release in the nucleus accumbens by directly stimulating ventral tegmental area neurons. Neuropsychopharmacology 32 : 1558-1569. CrossRef Medline

Rocha A, Kalivas PW (2010) Role of the prefrontal cortex and nucleus accumbens in reinstating methamphetamine seeking. Eur J Neurosci 31: 903-909. CrossRef Medline

Rosenberg NL, Grigsby J, Dreisbach J, Busenbark D, Grigsby P (2002) Neuropsychologic impairment and MRI abnormalities associated with chronic solvent abuse. J Toxicol Clin Toxicol 40:21-34. CrossRef Medline

Roth BL (2016) DREADDs for neuroscientists. Neuron 89:683-694. CrossRef Medline

Spear LP (2000) The adolescent brain and age-related behavioral manifestations. Neurosci Biobehav Rev 24:417-463. CrossRef Medline

Vialou V, Bagot RC, Cahill ME, Ferguson D, Robison AJ, Dietz DM, Fallon B, Mazei-Robison M, Ku SM, Harrigan E, Winstanley CA, Joshi T, Feng J, Berton O, Nestler EJ (2014) Prefrontal cortical circuit for depressionand anxiety-related behaviors mediated by cholecystokinin: role of DeltaFosB. J Neurosci 34:3878-3887. CrossRef Medline

Wayman WN, Woodward JJ (2017) Exposure to the abused inhalant toluene alters medial prefrontal cortex physiology. Neuropsychopharmacology. Advance online publication. Retrieved Jun. 7, 2017. CrossRef Medline

Weiss B, Wood RW, Macys DA (1979) Behavioral toxicology of carbon disulfide and toluene. Environ Health Perspect 30:39-45. CrossRef Medline

Willcocks AL, McNally GP (2013) The role of medial prefrontal cortex in extinction and reinstatement of alcohol-seeking in rats. Eur J Neurosci 37:259-268. CrossRef Medline 